\title{
Pretreatment Serum Levels of Soluble Cytokeratin Fragments (Cyfra 21-1, TPS, MonoTotal) in Relation to Clinical and Pathobiological Aspects of Head and Neck Squamous Cell Carcinomas
}

\author{
DAVID KALFERT ${ }^{1}$, JAROSLAV LUDVIK $^{2}$, RADEK KUCERA ${ }^{3}$, ONDREJ TOPOLCAN ${ }^{3}$, \\ PETR CELAKOVSKY ${ }^{4}$, MARTIN PESTA ${ }^{5}$, IVANA KHOLOVA ${ }^{6}$, JAN PLZAK $^{1}$ and MARIE LUDVIKOVA ${ }^{5}$ \\ ${ }^{1}$ Department of Otorhinolaryngology and Head and Neck Surgery, University Hospital Motol, \\ First Faculty of Medicine, Charles University, Prague, Czech Republic; \\ ${ }^{2}$ Departments of Imaging Methods, University Hospital Pilsen, Faculty of Medicine in Pilsen, \\ Charles University, Prague, Czech Republic; \\ ${ }^{3}$ Department of Immunochemistry, University Hospital Pilsen, Faculty of Medicine in Pilsen, \\ Charles University, Prague, Czech Republic; \\ ${ }^{4}$ Department of Otorhinolaryngology and Head and Neck Surgery, University Hospital Hradec Kralove, \\ Faculty of Medicine in Hradec Kralove, Charles University, Prague, Czech Republic; \\ ${ }^{5}$ Department of Biology, Faculty of Medicine in Pilsen, Charles University, Prague, Czech Republic; \\ ${ }^{6}$ Pathology, Fimlab Laboratories and Department of Pathology, \\ Faculty of Medicine and Health Technology, Tampere University, Tampere, Finland
}

\begin{abstract}
Background/Aim: The aim of this study was to analyze the pretreatment cytokeratin serum levels in head and neck squamous cell carcinoma (HNSCC) by three assays in relation to selected clinicopathological characteristics in an effort to find diagnostic/prognostic biomarkers for HNSCC and determine the best assay. Patients and Methods: In total, 46 patients with HNSCC with different subsite (oropharyngeal-21 cases, hypopharyngeal-4 and laryngeal21) were included in this prospective study. MonoTotal, Cyfra 21-1, and TPS radioimmunoassay kits were used to analyze cytokeratin fragments serum levels. Results: Statistically significant differences in serum levels of TPS and Cyfra 21-1 were found between low (stage I-II)- and high-stage (stage III-IV) tumors ( $p=0.0057 ; p=0.0138$ respectively). Cyfra21-1 assay showed significant differences between tumors of different sites with prominent elevation being found in oropharyngeal carcinomas and between patients with p16 positive and p16 negative HNSCC
\end{abstract}

Correspondence to: Jaroslav Ludvik, Department of Imagine Methods, University Hospital Pilsen, Faculty of Medicine in Pilsen, Charles University, Alej Svobody 80, 30460 Pilsen, Czech Republic. Tel: +42 0377103441, e-mail: ludvikj@fnplzen.cz

Key Words: Head and neck squamous cell carcinoma, Cyfra 21-1, TPS, MonoTotal, serum tumor marker, p16.
( $p=0.0242)$, being elevated in p16 positive tumors. Conclusion: The present study is the first to compare cytokeratin serum levels between various subgroups of HNSCC using three different assays. Cyfra 21-1 seems to be the most useful for clinical practice. The relation between elevated Cyfra 21-1 serum levels and p16 expression requires further investigation.

Head and neck squamous cell carcinoma (HNSCC) represents an aggressive tumor with unfavorable prognosis, with many cases of recurrent disease despite the improved therapy in the last decades. Despite the same histopathological type, HNSCC represents a heterogeneous group of tumors in respect to their different site of origin, etiology and pathobiology, clinical behavior and prognosis.

HNSCC with its clinicopathological and biological heterogeneity prompts the difficulties in the management of patients. The early detection of HNSCC remains a clinical challenge. On that account, a better understanding over the pathobiology of distinct site-specific types of HNSCC and the identification of novel molecules/diagnostic, prognostic and predictive biomarkers are required. This may help improve early detection, prognosis and therapeutic options for these tumor types. Different tissue and serum markers have been so far studied in HNSCC, but due to their low sensitivity and specificity these markers have not come to broad usefulness in clinical workflow as a sole diagnostic/prognostic tool (1-3). 
Cytokeratins (CK), also called as keratins, are the most commonly preferred marker for determination of epithelial tumors. The cytokeratins are specific for epithelial cells and the cytokeratin pattern is usually preserved during the transformation of normal cells into malignant cells. The primary function of $\mathrm{CK}$ is to protect epithelial cells from different types of stresses that result in cell death (4). At present, more than 37 different human CK genes have been identified, of which CK 8, 18, and 19 are the most abundant in carcinomas $(5,6)$.

CK can be detected either as partially degraded single protein fragments, as small complexes, or as large polymeric protein complexes in several body fluids including blood, urine, cyst fluids, ascites, pleural effusions etc. $(4,5)$. In patients with carcinomas the levels of CK are significantly higher than in apparently healthy individuals (5). Several assays measuring serum cytokeratin have been introduced, namely tissue polypeptide-specific antigen-cytokeratin fragments 8 and 18 (TPS), cytokeratin 19 fragment (Cyfra 211), and fragments of CK 8,18 and 19 (MonoTotal). The identification of reliable tumor markers for HNSCC is expected to facilitate early diagnosis, predict prognosis, as well as assist in therapy options and modifications for patients.

The goal of this study was to analyze the pretreatment cytokeratin serum levels by three assays - TPS, Cyfra 21-1, and MonoTotal in HNSCC in relationship to location of cancers and selected clinicopathological characteristics of these tumors. We aimed to contribute to the explanation of the pathobiology of site-specific subgroups of HNSCC and clarify whether pretreatment cytokeratin serum levels may serve as a diagnostic/prognostic biomarker for site-specific subgroups of HNSCC and also determine the best assay for this analysis.

\section{Patients and Methods}

Patient population. A total of 46 patients with primary diagnosis of HNSCC were included in this prospective study. Patients were enrolled in the study that began in July 2011 and closed for new patient accrual in December 2012. The diagnosis in all patients was histologically verified and the following site-specific subgroups of HNSCC were specified: oropharyngeal (21 cases), hypopharyngeal (4 cases) and laryngeal (21 cases). An integral part of the final histological diagnosis was immunohistochemical determination of p16 status in all HNSCCs that belongs to routine practice in our University Hospital. Clinicopathological data and follow-up information for all the patients were available. The median age of patients at the time of diagnosis was 60 years (men 59.5, women 60) with a range $=46-85$ years. A total of 34 patients were smokers. Patients with other malignancies, inflammatory and infectious diseases were excluded from this study. The tumor extent was assessed by physical examination and imaging methods (CT scan and MRI). Tumor grade was evaluated following World Health Organization (WHO) criteria and tumor staging was determined using the TNM system (7th edition) of the International Union Against Cancer (7). Data relevant to grading, staging, p16 status and other characteristics of cancers were retrieved from the hospital's information system. Follow-up was 12-76 months. All patients provided written informed consent, in accordance with the principles of the Declaration of Helsinki. The present study was approved by the Ethics Committee of University Hospital (number 201105 S14P). Treatment decision-making was based on the clinical status of patients and on the grading and staging of tumors. All the patients underwent surgery followed by radiotherapy or chemoradiotherapy.

Blood serum collection and procedures. Ten milliliters of peripheral blood were drawn from every patient before surgery from 7 to 9 a.m. using standardized phlebotomy procedures. Blood samples were collected without anticoagulant into red top vacutainers and allowed to coagulate for 20 to $30 \mathrm{~min}$ at room temperature. Sera were separated by centrifugation of blood for $10 \mathrm{~min}$ at $1,700 \times \mathrm{g}$. All specimens were immediately aliquoted and stored at $-80^{\circ} \mathrm{C}$ until the time of analysis.

Sample analysis. MonoTotal serum levels were measured using the radioimmunoassay kit IRMA MonoTotal (IDL Biotech, Bromma, Sweden). The monoclonal antibodies used in the MonoTotal assay are directed to the epitopes on cytokeratin fragments 8,18 and 19. Cyfra 21-1 serum levels were measured using the radioimmunoassay kit IRMA Cytokeratin 19 Fragment (Beckman Coulter, Immunotech, Prague, Czech Republic). TPS serum levels were measured using the radioimmunoassay kit IRMA TPS (IDL Biotech, Bromma, Sweden). The monoclonal antibody used in the IRMA TPS assay is directed to the epitope on cytokeratin fragment 18 . All analyses were performed at the Stratec SR 300 instrument.

Statistical analysis. The results obtained in our study were statistically analyzed. Quantitative data are expressed as the mean \pm standard deviation (SD) and median. The Spearman's rank order test was performed for the comparison of multiple groups of tumors. The Wilcoxon two-sample test and Kruskal-Wallis test were used for estimation of statistical significance for association between serum levels of soluble cytokeratins (Cyfra 21-1, TPS, MonoTotal) and clinicopathological parameters. $p$-Value less than 0.05 was considered to indicate a statistically significant difference. Statistical analysis was carried out using SAS 9.23 software (Statistical Analysis Software release 9.3. SAS Institute Inc., Cary, NC, USA).

\section{Results}

Serum levels of Cyfra 21-1, TPS, and MonoTotal were compared in all carcinomas together (irrespective of tumor site) and separately in each of the three subgroups (oropharyngeal, laryngeal and hypopharyngeal) of HNSCC. The evaluation was focused on the correlation between serum levels of Cyfra 21-1, TPS, and MonoTotal and the site of tumor, and the relationship between serum concentration of Cyfra 21-1, TPS, and MonoTotal and selected clinicopathological features of HNSCC (TNM staging, grading, lymph node status, p16 status, recurrence, and gender age and smoking habit of patients as well).

Statistically significant correlations were confirmed between TPS and Cyfra 21-1 levels ( $\mathrm{r}=0.327, p=0.027)$, between TPS and MonoTotal levels $(\mathrm{r}=0.684, p<0.01)$, and 
Table I. Serum cytokeratin levels analysed by three assays in relationship to various clinicopathological parameters of HNSCC.

\begin{tabular}{|c|c|c|c|c|c|c|c|c|c|c|}
\hline \multirow{3}{*}{ Clinicopathological parameters } & \multirow{3}{*}{$\mathrm{N}$} & \multicolumn{9}{|c|}{ Assay/Serum levels } \\
\hline & & \multicolumn{3}{|c|}{ MonoTotal } & \multicolumn{3}{|c|}{ TPS } & \multicolumn{3}{|c|}{ Cyfra 21-1 } \\
\hline & & Mean (IU/1) & SD & $p$-Value & Mean (IU/1) & SD & $p$-Value & Mean $(g / 1)$ & $\mathrm{SD}$ & $p$-Value \\
\hline \multicolumn{11}{|l|}{ Gender } \\
\hline male & 38 & 92.01 & 68.77 & $\mathrm{NS}^{\mathrm{a}}$ & 161.26 & 124.11 & $0.05^{\mathrm{a}}$ & 2.78 & 2.36 & $\mathrm{NS}^{\mathrm{a}}$ \\
\hline female & 8 & 57.59 & 30.34 & & 99.06 & 44.42 & & 3.24 & 4.24 & \\
\hline \multicolumn{11}{|l|}{ Age } \\
\hline$\leq 60$ & 28 & 81.52 & 53.43 & $\mathrm{NS}^{\mathrm{a}}$ & 141.60 & 106.52 & $\mathrm{NS}^{\mathrm{a}}$ & 2.68 & 2.26 & $\mathrm{NS}^{\mathrm{a}}$ \\
\hline$>60$ & 18 & 93.04 & 80.72 & & 164.18 & 132.26 & & 3.12 & 3.37 & \\
\hline \multicolumn{11}{|l|}{ Abusus } \\
\hline Non-smoker & 14 & 74.15 & 36.47 & $\mathrm{NS}^{\mathrm{a}}$ & 120.79 & 50.30 & $\mathrm{NSa}$ & 3.49 & 3.36 & $\mathrm{NS}^{\mathrm{a}}$ \\
\hline Smoker & 32 & 91.06 & 73.91 & & 163.41 & 134.25 & & 2.58 & 2.40 & \\
\hline \multicolumn{11}{|l|}{ TNM staging } \\
\hline Stage I-II & 13 & 60.32 & 30.04 & $\mathrm{NS}^{\mathrm{a}}$ & 91.92 & 38.41 & $0.0057^{\mathrm{a}}$ & 1.60 & 0.42 & $0.0138^{\mathrm{a}}$ \\
\hline Stage III-IV & 33 & 96.15 & 72.13 & & 173.49 & 128.64 & & 3.35 & 3.07 & \\
\hline \multicolumn{11}{|l|}{ Nodal status } \\
\hline N1-3 & 26 & 104.96 & 77.01 & $0.0409^{\mathrm{a}}$ & 184.41 & 142.98 & $\mathrm{NS}^{\mathrm{a}}$ & 3.65 & 3.28 & $0.0057^{\mathrm{a}}$ \\
\hline No & 20 & 61.41 & 32.11 & & 106.28 & 39.18 & & 1.83 & 1.19 & \\
\hline \multicolumn{11}{|l|}{ Grading } \\
\hline G1-2 & 32 & 82.70 & 55.53 & $\mathrm{NS}^{\mathrm{a}}$ & 149.09 & 117.43 & $\mathrm{NS}^{\mathrm{a}}$ & 2.57 & 2.81 & $\mathrm{NS}^{\mathrm{a}}$ \\
\hline G3 & 14 & 93.63 & 84.38 & & 153.53 & 118.19 & & 3.50 & 2.47 & \\
\hline \multicolumn{11}{|l|}{ p16 status } \\
\hline p16 positive & 17 & 80.33 & 43.29 & NSa & 121.66 & 46.97 & $\mathrm{NS}^{\mathrm{a}}$ & 3.64 & 3.47 & $0.0242^{\mathrm{a}}$ \\
\hline p16 negative & 29 & 89.36 & 75.22 & & 167.31 & 140.37 & & 2.40 & 2.10 & \\
\hline \multicolumn{11}{|l|}{ Anatomic site } \\
\hline Oropharynx & 21 & 79.55 & 39.62 & $\mathrm{NS}^{\mathrm{b}}$ & 122.71 & 43.27 & $\mathrm{NS}^{\mathrm{b}}$ & 3.53 & 3.27 & $0.0115^{\mathrm{b}}$ \\
\hline Hypopharynx & 4 & 109.13 & 92.74 & & 234.64 & 208.04 & & 3.13 & 2.65 & \\
\hline Larynx & 21 & 88.09 & 80.31 & & 162.13 & 140.47 & & 2.13 & 1.95 & \\
\hline \multicolumn{11}{|l|}{ Recurrence } \\
\hline No-recurrence/no-persistence & 33 & 77.47 & 49.18 & NSa & 138.82 & 88.45 & NSa & 2.89 & 2.88 & NSa \\
\hline Recurrence/persistence & 13 & 107.72 & 92.82 & & 179.94 & 169.11 & & 2.77 & 2.37 & \\
\hline
\end{tabular}

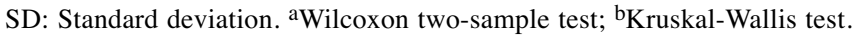

between Cyfra 21-1 and MonoTotal levels ( $\mathrm{r}=0.553, p<0.01)$ in the studied cohort of tumors.

In respect to Cyfra 21-1 serum levels in each of three subgroups of HNSCC, significant differences were found between oropharyngeal, laryngeal and hypopharyngeal tumors $(p=0.0115)$, with higher Cyfra 21-1 levels being found in oropharyngeal carcinomas.

Moreover, statistically significant differences in serum levels of TPS and Cyfra 21-1 were found between low stage (stage I-II) and high stage (stage III-IV) tumors $(p=0.0057$; $p=0.0138$ respectively) with higher serum values of both markers in high stage tumors. Higher serum Cyfra 21-1 and MonoTotal levels were statistically significant in patients with nodal involvement ( $p=0.0057 ; p=0.0409$ respectively) in comparison with those without lymph node metastases. Statistically significant differences were found in serum Cyfra 21-1 levels between patients with p16-positive and p16negative HNSCC $(p=0.0242)$, with higher Cyfra 21-1 levels in p16-positive tumors. All results are shown in Table I.
For laryngeal cancer, there were significant differences in serum TPS levels between low stage (stage I-II) and high stage (stage III-IV) tumors $(p=0.0093)$ with higher TPS levels being found in high stage tumors, as well as between positive lymph node and negative lymph node status ( $p=0.0277)$ with higher TPS levels being found in positive lymph node status.

No significant differences between serum Cyfra 21-1, TPS, and MonoTotal levels and clinicopathological characteristics of oropharyngeal and hypopharyngeal cancer were found.

\section{Discussion}

The current system of diagnostic assessments of tumor stage and surgical margins in HNSCC has limited ability to stratify patients according to the specific risk of metastasis, localregional recurrence or the development of a second primary. There is need for the development of biomarkers for 
pathobiological characterization of tumors. Serum diagnostic, predictive or prognostic markers play important roles in the clinical management of many cancers, therefore, also in HNSCC these markers are intensively studied in attempts to achieve more than a marginal improvement in these neoplasms' outcome $(1,8)$.

Cytokeratins are a member of the family of intermediate filament proteins primarily located in epithelial cells. At present, more than 20 different cytokeratins have been identified being epithelial cell specific. The cytokeratin pattern is usually preserved during the transformation of normal cells into malignant cells. Low-molecular weight cytokeratins 8,18 and 19 are the most abundant in epithelial cells and are expressed by most types of carcinomas. Cytokeratin leakage into serum is associated with cell death and cancer progression due to proteolytic cleavage (9). Cytokeratins are present in the serum usually in the form of complexes of soluble fragments (9).

In our study we focused on pretreatment analysis of soluble fragments of cytokeratins by using commercially available serum assays TPS, Cyfra 21-1 and MonoTotal in attempts to determine their diagnostic and/or prognostic role in HNSCC. The diagnostic kit for TPS contains an antibody against cytokeratin fragment 18 (10). The Cyfra 21-1 assay uses two monoclonal antibodies against epitopes on the cytokeratin fragment 19. TPS and Cyfra 21-1 have been so far suggested to be promising markers in different cancers including lung, breast, ovarian, oral, and gastrointestinal cancers (4). Notably, they have been shown for a long time to be useful prognostic markers in HNSCC as well $(4,11-$ 15). MonoTotal is a novel cytokeratin immunoassay that specifically measures defined epitopes of CK8, CK18 and CK19 (16). MonoTotal is generally considered to be a highly sensitive marker of tumor cell activity. Its diagnostic and prognostic significance was evaluated in non-small cell lung cancer (NSCLC), esophageal cancer, and liver metastases as well $(6,16-18)$. However, we are aware of only one study of MonoTotal in HNSCC that was performed in a group of 32 patients with histologically confirmed squamous cell carcinoma of head and neck without more detailed site specifications. MonoTotal has been confirmed as a promising prognostic serum marker (19). In the present study we revealed a significant correlation between serum concentrations of all three studied markers in HNSCC patients, suggesting the growth activity of carcinomas. Nevertheless, MonoTotal showed the best correlation parameters $(p=0.01)$, and the most elevated serum levels. Taking into consideration the site of tumors, we found some differences in serum concentrations of cytokeratins between tumors of various locations. Cyfra 21-1 demonstrated significantly higher serum levels in patients with oropharyngeal cancers $(p=0.0115)$. However, significant sitespecific differences of serum cytokeratin levels measured by
TPS and MonoTotal were not confirmed in our study. Nevertheless, the Cyfra 21-1 assay uses two monoclonal antibodies against epitopes on the cytokeratin fragment 19, therefore, probably its specificity is the best (20). Relationship between site of tumor and serum levels of Cyfra 21-1 has been also described by Ceruse et al. (21). In his study, laryngeal cancer showed significantly lower serum levels. The significant site-specific differences in serum levels of particular cytokeratin markers may be explained by different patterns of cytokeratin expression in stratified squamous epithelium of the upper and lower respiratory tract as well $(22,23)$. As reported by another study, two pathogenetic pathways in the evolution of oral squamous cell cancers characterized by a different expression of cytokeratins have been suggested. Low-molecular weight CK 8, 18 and 19 immunohistochemical expression are associated with high-grade, while high-molecular weight ones with lowgrade oral squamous cancer (24). Similarly, we also found a relation between elevation of $\mathrm{CKs}$, tumor grade and anatomical sublocation of HNSCC.

Irrespective of tumor site of HNSCC some significant differences in serum levels were discovered in relationship to clinicopathological characteristics of tumors in the presented study. Statistically significant differences in serum levels of cytokeratins between high stage and low stage cancers and between carcinomas with lymph node metastases and lymph node negative tumors were also confirmed. Thus, our results are in agreement with known facts about significantly higher serum levels of cytokeratins in advanced cancer $(24,25)$. The majority of authors came to the similar conclusions not only in HNSCC $(15,21)$, but predominantly in lung cancer $(10,17$, 26). Not just elevated serum levels, but also increased CK 8 , 18 and 19 expression in neoplastic tissue may represent negative prognostic factors of HNSCC (27-29). However, Büntzel et al. did not find a significant relationship between lymph node metastasis and the levels of Cyfra 21-1 in patients with advanced HNSCC (30). The most commonly studied cytokeratin markers/assays in different types of cancer including HNSCC have so far been TPS and Cyfra 21-1. In this respect, our analysis of MonoTotal serum levels in HNSCC seems to be extraordinary, however, it was not superior to the other two cytokeratin assays. In the study by Prazakova et al. Elevated serum levels of MonoTotal were associated with advanced stages of squamous cell carcinoma (6). Prazakova et al. suggested that MonoTotal may be used as a prognostic marker in NSCLC (6). Likewise, serum levels of MonoTotal were significantly higher in patients with nodal involvement in our study ( $p=0.0409)$. Brattstrom et al. also published similar results in patients with esophageal cancer (16). Although we did not note significant differences between assay/serum levels and age of patients, the other authors demonstrated significantly higher immunohistochemical CK19 expression in the older patients (male age group $\geq 50$ years) (31). 
Currently, the correlation between increased serum cytokeratin levels and tumor diagnosis/prognosis has become a major concern. By some authors, Cyfra 21-1 is an unsatisfactory marker for detection of primary cancer, but a useful screening indicator of distant metastases or locoregional recurrence $(23,32,33)$. These markers can draw attention not only as pretreatment prognostic markers, but also as dynamic markers for monitoring HNSCC followup. However, the evaluation of Cyfra 21-1 levels must be done with caution as elevation of cytokeratin markers could be associated with foregoing radiotherapy rather than recurrence of cancer $(14,34)$. Similarly, the necessity of the optimal timing for sample collection for TPS testing after adjuvant chemotherapy and radiotherapy of breast cancer was revealed in the study by Svobodova et al. (35). Surprisingly, in the present study we found significant differences in Cyfra 21-1 serum levels between p16-positive and p16-negative HNSCC with increased levels in p16 positive tumors. Nevertheless, the association between CK19 up-regulation and HPV-related oral/oropharyngeal HNSCC has been demonstrated by Santoro et al. to be explained by the high-risk HPV-mediated deregulation of cytokeratin expression profile in stratified squamous epithelium (29). As p16-positive HNSCCs are supposed to have better prognosis, while elevated Cyfra 21-1 levels are probably associated with worse prognosis of HNSCC, our results seem to be somewhat contradictory (36). We are not aware of any study focused on the relationship between serum soluble cytokeratin fragments levels and p16 expression in HNSCC. However, our analysis is limited by the fact that all p16-positive cases arose in the oropharynx only and that the number of tumors investigated in the present study is too small to allow for a definite conclusion. Therefore, the abovementioned data promote a question concerning the interactions between the elevation of CKs and the expression of p16 (robust marker of HPV infection in HNSCC), that need to be better elucidated $(37,38)$.

\section{Conclusion}

The present study is the first to compare cytokeratin serum levels between different subgroups of HNSCC (oropharyngeal, hypopharyngeal, and laryngeal) using three different commercially available assays. The relationship between cytokeratin concentrations and clinicopathological characteristics was also analyzed. All three markers correlated with each other, while the most useful one for clinical practice was not determined, although Cyfra 21-1 has commonly shown significant results pointing to the fact that it could be the most promising prognostic marker. The relationship between elevated Cyfra 21-1 serum levels and p16 expression in oropharyngeal cancer requires further study.

\section{Conflicts of Interest}

The Author(s) declared no potential conflicts of interest regarding this study.

\section{Authors' Contributions}

DK conceived the study idea and designed the study, collected samples and clinical data, contributed to analysis and interpretation of data and writing, review, revision and editing of the manuscript; $\mathrm{JL}$ contributed to acquisition, analysis and interpretation of data and technical support, reviewed the literature and contributed to review and editing of manuscript; RK and OT conducted the experiments and critically reviewed the manuscript; PC contributed to clinical data and samples collection; JP discussed selected results; IK critically reviewed the manuscript; JP reviewed the manuscript and discussed the results; ML contributed to project planning, analyzed the data, interpreted p16 immunohistochemical staining and statistical analysis, wrote the manuscript and supervised the study. All Authors read and approved the final manuscript.

\section{Acknowledgements}

This study was supported by the Ministry of Health, Czech Republic Conceptual Development of Research Organization (University Hospital in Pilsen-FNPl, 00669806) and by the Charles University Research Fund (Progres Q39 and Progres Q28/LF1(UNCE 204013). This study is a result of the research funded by the Czech Science Foundation, grant nr. 18-03978S. IK was supported by VTR grants of Pirkanmaa Hospital District and Pirkanmaa Cancer Foundation.

\section{References}

1 Mehta M: Tumor markers for head and neck cancer: A review. J Adc Med Dent Scie Res 3(5): S60, 2015.

2 Negi M, Bansal S, Puri A and Nangia R: Tumor markers in oral squamous cell carcinoma as an adjunct to diagnosis: An insight. Indian J Dent Sci 10(3): 190-195, 2018. DOI: 10.4103/ ijds.Ijds_53_18

3 Novák Š, Bandurová V, Mifková A, Kalfeřt D, Fík Z, Lukeš P, Szabó P, Plzák J and Smetana Jr. K: Tumor microenvironment. Otorinolaryng a Foniat /Prague/ 68(1): 41-51, 2019.

4 Sawant SS, Zingde SM and Vaidya MM: Cytokeratin fragments in the serum: Their utility for the management of oral cancer. Oral Oncol 44(8): 722-732, 2008. PMID: 18203649. DOI: 10.1016/j.oraloncology.2007.10.008

5 Barak V, Goike H, Panaretakis KW and Einarsson R: Clinical utility of cytokeratins as tumor markers. Clin Biochem 37(7): 529-540, 2004. PMID: 15234234. DOI: 10.1016/ j.clinbiochem. 2004.05.009

6 Prazakova M, Vrzalova J, Auge JM, Safranek J, Topolcan O, Fuchsova R, Spisakova M, Svobodova S, Holubec L, Jr. and Pesta M: The role of MonoTotal in the primary diagnosis, prognosis and follow-up of patients with non-small cell lung cancer (NSCLC). Anticancer Res 31(9): 3107-3112, 2011. PMID: 21868567.

7 Sobin LH, Gospodarowicz MK and Wittekind C: TNM classification of malignant tumours, 7 th edition. 7 th edn. WileyBlackwell, 2009. 
8 Vsiansky V, Svobodova M, Gumulec J, Cernei N, Sterbova D, Zitka O, Kostrica R, Smilek P, Plzak J, Betka J, Kalfert D, Masarik M and Raudenska M: Prognostic significance of serum free amino acids in head and neck cancers. Cells 8(5), 2019. PMID: 31075822. DOI: 10.3390/cells8050428

9 Linder S, Olofsson MH, Herrmann R and Ulukaya E: Utilization of cytokeratin-based biomarkers for pharmacodynamic studies. Expert Rev Mol Diagn 10(3): 353-359, 2010. PMID: 20370591. DOI: $10.1586 /$ erm.10.14

10 Kucera R, Topolcan O, Fiala O, Kinkorova J, Treska V, Zednikova I, Slouka D, Simanek V, Safanda M and Babuska V: The role of TPS and TPA in the diagnostics of distant metastases. Anticancer Res 36(2): 773-777, 2016. PMID: 26851038.

11 Doweck I, Barak M, Greenberg E, Uri N, Kellner J, Lurie M and Gruener N: Cyfra 21-1. A new potential tumor marker for squamous cell carcinoma of head and neck. Arch Otolaryngol Head Neck Surg 121(2): 177-181, 1995. PMID: 7530966.

12 Molina R, Torres MD, Moragas M, Filella X, Jo J, Gimenez N, Traserra $\mathrm{J}$ and Ballesta AM: Prognostic value of tps in patients with head and neck malignancies: Comparison with scc. Anticancer Res 15(2): 479-484, 1995. PMID: 7763026.

13 Bongers V, Braakhuis BJ and Snow GB: Circulating fragments of cytokeratin 19 in patients with head and neck squamous cell carcinoma. Clin Otolaryngol Allied Sci 20(5): 479-482, 1995. PMID: 8582085.

14 Doweck I, Barak M, Uri N and Greenberg E: The prognostic value of the tumour marker cyfra 21-1 in carcinoma of head and neck and its role in early detection of recurrent disease. Br J Cancer 83(12): 1696-1701, 2000. PMID: 11104568. DOI: 10.1054/bjoc.2000.1502

15 Barak V, Meirovitz A, Leibovici V, Rachmut J, Peretz T, Eliashar R and Gross M: The diagnostic and prognostic value of tumor markers (CEA, SCC, CYFRA 21-1, TPS) in head and neck cancer patients. Anticancer Res 35(10): 5519-5524, 2015. PMID: 26408719.

16 Brattstrom D, Wagenius G, Sandstrom P, Dreilich M, Bergstrom $\mathrm{S}$, Goike H, Hesselius $\mathrm{P}$ and Bergqvist M: Newly developed assay measuring cytokeratins 8,18 and 19 in serum is correlated to survival and tumor volume in patients with esophageal carcinoma. Dis Esophagus 18(5): 298-303, 2005. PMID: 16197528. DOI: $10.1111 / \mathrm{j} .1442-2050.2005 .00504 . x$

17 Fiala O, Pesek M, Finek J, Svaton M, Sorejs O, Bortlicek Z, Kucera R and Topolcan O: Prognostic significance of serum tumor markers in patients with advanced-stage nsclc treated with pemetrexed-based chemotherapy. Anticancer Res 36(1): 461466, 2016. PMID: 26722082.

18 Špišáková M, Kučera R, Topolčan O, Šafanda M, Slouka D, Kinkorová $\mathrm{J}$ and Třeška V: The use of soluble cytokeratin fragments in the diagnosis of liver metastases. Klin Biochem Metab 23(3): 95-99, 2015.

19 Stasik Z, Wójcik E and Mucha-Małecka A: Diagnostic usefulness of SCC-Ag, Cyfra 21-1, MonoTotal, and selected acute phase proteins in head and neck cancer patients. Diagn Lab 45(2): 179-183, 2009.

20 Uenishi T, Kubo S, Hirohashi K, Tanaka H, Shuto T, Yamamoto $\mathrm{T}$ and Nishiguchi S: Cytokeratin-19 fragments in serum (cyfra 211) as a marker in primary liver cancer. Br J Cancer 88(12): 18941899, 2003. PMID: 12799633. DOI: 10.1038/sj.bjc.660 1026

21 Ceruse P, Rabilloud M, Charrie A, Dubreuil C and Disant F: Study of cyfra 21-1, a tumor marker, in head and neck squamous cell carcinoma. Ann Otol Rhinol Laryngol 114(10): 768-776, 2005. PMID: 16285267. DOI: 10.1177/000348940511401006
22 Nagle RB, Moll R, Weidauer H, Nemetschek H and Franke WW: Different patterns of cytokeratin expression in the normal epithelia of the upper respiratory tract. Differentiation 30(2): 130-140, 1985. PMID: 2420672.

23 Kuropkat C, Lippert BM and Werner JA: Follow-up with serum Cyfra 21-1 in patients with squamous cell carcinomas of the head and neck. Oncology 63(3): 280-285, 2002. PMID: 12381908. DOI: $10.1159 / 000065476$

24 Frohwitter G, Buerger H, PJ VAND, Korsching E, Kleinheinz J and Fillies T: Cytokeratin and protein expression patterns in squamous cell carcinoma of the oral cavity provide evidence for two distinct pathogenetic pathways. Oncol Lett 12(1): 107-113, 2016. PMID: 27347109. DOI: 10.3892/ol.2016.4588

25 Banal A, Hacene K, Berthelot-Ruff E, Mahe E, Fontana X and Pichon MF: Comparison of Cyfra 21-1 and SCC assays in head and neck tumours. Tumour Biol 22(1): 27-35, 2001. PMID: 11054024. DOI: $10.1159 / 000030152$

26 Fiala O, Pesek M, Finek J, Benesova L, Minarik M, Bortlicek Z and Topolcan O: Predictive role of CEA and CYFRA 21-1 in patients with advanced-stage NSCLC treated with erlotinib. Anticancer Res 34(6): 3205-3210, 2014. PMID: 24922695.

27 Fillies T, Werkmeister R, Packeisen J, Brandt B, Morin P, Weingart D, Joos U and Buerger H: Cytokeratin 8/18 expression indicates a poor prognosis in squamous cell carcinomas of the oral cavity. BMC Cancer 6: 10, 2006. PMID: 16412231. DOI: 10.1186/1471-2407-6-10

28 DE Paz D, Young CK, Chien HT, Tsao CK, Fok CC, Fan KH, Liao CT, Wang HM, Kang CJ, Chang JT and Huang SF: Prognostic roles of SCC antigen, CRP and CYFRA 21-1 in oral cavity squamous cell carcinoma. Anticancer Res 39(4): 20252033, 2019. PMID: 30952746. DOI: 10.21873/anticanres.13313

29 Santoro A, Pannone G, Ninivaggi R, Petruzzi M, Santarelli A, Russo GM, Lepore S, Pietrafesa M, Laurenzana I, Leonardi R, Bucci P, Natalicchio MI, Lucchese A, Papagerakis S and Bufo P: Relationship between CK19 expression, deregulation of normal keratinocyte differentiation pattern and high risk-human papilloma virus infection in oral and oropharyngeal squamous cell carcinoma. Infect Agent Cancer 10: 46, 2015. PMID: 26672675. DOI: 10.1186/s13027-015-0041-x

30 Buntzel J, Hornig A, Glatzel M, Micke O, Bruns F, Schafer U and Frohlich D: Tumor markers and lymphatic metastasis in head and neck cancer patients. Anticancer Res 25(3A): 15391542, 2005. PMID: 16033056.

31 Babiker AY, Rahmani AH, Abdalaziz MS, Albutti A, Aly SM and Ahmed HG: Expressional analysis of p16 and cytokeratin19 protein in the genesis of oral squamous cell carcinoma patients. Int J Clin Exp Med 7(6): 1524-1530, 2014. PMID: 25035775.

32 Hoffmann-Fazel A, Hoffmann M, Gottschlich S, Maass JD, Rudert $\mathrm{H}$ and Maune S: Cyfra 21-1 in diagnosis of distant metastases of head and neck carcinoma. Anticancer Res 23(2A): 917-920, 2003. PMID: 12820323.

33 Alkotyfan K, Wiegand S, Muller HH, Windfuhr JP, Werner JA and Sesterhenn AM: Cyfra 21-1 as a tumor marker for followup of patients with squamous cell carcinoma of the oropharynx. Anticancer Res 30(6): 2291-2296, 2010. PMID: 20651382.

34 Pradier O, Hille A, Schmiberger H and Hess CF: Monitoring of therapy in head and neck patients during the radiotherapy by measurement of Cyfra 21-1. Cancer Radiother 6(1): 15-21, 2002. PMID: 11899676. 
35 Svobodova S, Kucera R, Fiala O, Karlikova M, Narsanska A, Zednikova I, Treska V, Slouka D, Rousarova M, Topolcan O and Finek J: CEA, CA 15-3, and TPS as prognostic factors in the follow-up monitoring of patients after radical surgery for breast cancer. Anticancer Res 38(1): 465-469, 2018. PMID: 29277810. DOI: 10.21873 /anticanres.12245

36 Sudhoff HH, Schwarze HP, Winder D, Steinstraesser L, Gorner M, Stanley M and Goon PK: Evidence for a causal association for HPV in head and neck cancers. Eur Arch Otorhinolaryngol 268(11): 1541-1547, 2011. PMID: 21792686. DOI: 10.1007/ s00405-011-1714-8

37 Thomas $\mathrm{J}$ and Primeaux T: Is p16 immunohistochemistry a more cost-effective method for identification of human papilloma virus-associated head and neck squamous cell carcinoma? Ann Diagn Pathol 16(2): 91-99, 2012. PMID: 22197546. DOI: 10.1016/j.anndiagpath.2011.09.002

38 Konig F, Krekeler G, Honig JF, Cordon-Cardo C, Fischer G and Korabiowska M: Relation between human papillomavirus positivity and p16 expression in head and neck carcinomas - a tissue microarray study. Anticancer Res 27(1A): 283-288, 2007. PMID: 17352245.
Received July 8, 2019

Revised July 11, 2019

Accepted July 12, 2019 